\title{
Developing Imitation Ability in Organizational Behavior and Psychology
}

\author{
Fahri Özsungur* \\ Mersin University, Turkey \\ *Corresponding author: Fahri Ozsungur, Mersin University, Turkey
}

\section{ARTICLE INFO}

Received: 幽 June 14, 2021

Published: 幽 July 02, 2021

Citation: Fahri Özsungur. Developing Imitation Ability in Organizational Behavior and Psychology. Biomed J Sci \& Tech Res 36(5)-2021. BJSTR. MS.ID.005925.

Keywords: Organizational Behavior; Organizational Psychology; Organization Imitation; Defensive Imitation Ability; Mirror Neuron System

\begin{abstract}
ABSTACT
The aim of this study is to prove whether imitation ability can be developed in organizational behavior and psychology. The study was carried out with joint-stock companies, public institutions, and professional organizations operating in five different provinces and countries (375 participants). Five managers from each sample unit were included in this study, which was carried out in 2020 and 2021. The phenomenological method, one of the qualitative research methods, was adopted in the study. The data obtained through the interview were coded, classified, and categorized. Research results revealed that human behavior and psychology are imitated by organizations. According to the coding results, three types of imitation behaviors were identified in the context of organizational behavior: defense, strategic attack, passive action behaviors. Defensive imitation ability in organizational behavior consisted of defense for existence, competition defense, sustainability/adaptation defense, resource dependency defense, organizational psychology defense. It was determined that the imitation ability of organizational psychology consisted of traffic (psycho technical ability), health and clinical, training, forensic, and counseling psychology categories.
\end{abstract}

Abbreviations: SLE: Systemic Lupus Erythematosus; R: Researcher; EC: Expert Committee

\section{Introduction}

Human psychology is an unknown multifactorial cosmos [1]. The psychology cosmos reveals the aspects of human beings that differ from the psychology of other living things day by day. The complexity in the development of behaviors and the structure of psychology affecting human cognitive processes are the subject of research in many fields of science [2]. The positive and negative effects of psychology on human behavior emerge as a result of environmental and pathological factors [3]. These factors shape and direct the behavior of individuals. The fact that human behavior is under the influence of various factors causes the effects of psychology to become more complex [4]. One of these complex effects is imitation behaviors [5]. Imitation behavior emerges as a result of pushing human psychology to repeat the observed events that occur in the cognitive process [6]. The neuropsychological and systemic mirror neuron effect is an important function that activates the human defense system [7]. The mirror neuron system, which people activate for adaptation to the environment, facilitates learning about other living things thanks to its imitation ability [8]. Behaviors are simulated by observing the movements of living things through imitation [9-11]. Diseases that Systemic Lupus Erythematosus (SLE) patients observed are imitated.

In a study on this subject, it was revealed that SLE causes psychological signs of aging [11]. According to another study, the effect of menstruation on the perception of aging through the imitation of menopause was proven [9]. Other studies on the perception of aging, latent aging, and the pathological and psychological effects of imitation ability clearly reveal the complex and influencing nature of this ability of human psychology [12]. The functional contribution of the mirror neuron system in humans to the ability to imitate enables to simulate the planning for the future and to reveal the knowledge-seeking behavior [13]. This defense and future planning strategy emerges as a result of the 
complex and perfect neuropsychological functions of humans [14]. Although pathological studies have revealed neuropsychological evidence of disease, the effects of human mimicry/imitation on their environment have not been investigated. The imitation effects on organizations, businesses, systems, and cyber elements created by people are important and remarkable issues. The aim of this study is to prove whether imitation ability can be developed in organizational behavior and psychology.

\section{Methodology}

\section{Sample Selection}

The study was carried out with joint-stock companies, public institutions, and professional organizations operating in five different provinces and countries. Five managers from each sample unit were included in this study, which was carried out in 2020 and 2021. Two interviews were held with the managers, one year apart. In the Interview, the questions in the Appendix 1 were directed to the participants. The interview with the participants was carried out through Google meet. The contact information of the sample was obtained through LinkedIn and Google search engines. The five units, each accepting the research proposals sent to 211 companies, 98 public institutions, and 78 professional organizations, were included in the study. It was foreseen that the units selected from the groups in which the research would be carried out were equal, which would ensure the generalizability of the results and the objectivity of each unit's contribution to the sample. All participants were informed about the title, cause, and results of the study, and that it was carried out on a voluntary basis with an online consent form. 32 participants who did not accept to participate in the study were excluded from the study. As a result, 5 participants from each research group who accepted to participate in the study voluntarily were included in the study. The group, city, and country information included in the study are shown in Table 1. As can be seen from Table 1, the total number of units in each group included in the sample is 25 and the number of participants is 125 . A total of 375 participants were included in the study. Demographic information of the participants is presented in Table 2 .

Table 1: Sampling data.

\begin{tabular}{|c|c|c|c|c|c|c|c|c|c|}
\hline Country/Group & Joint-Stock Company & $\mathbf{n}^{\mathrm{g}}$ & $n^{p}$ & Public İnstitution & $\mathbf{n}^{\mathrm{g}}$ & $\mathbf{n}^{\mathrm{p}}$ & Professional Organization & $\mathbf{n}^{\mathrm{g}}$ & $\mathbf{n}^{\mathrm{p}}$ \\
\hline England & London & 5 & 25 & London & 5 & 25 & London & 5 & 25 \\
\hline Romania & Bucharest & 5 & 25 & Bucharest & 5 & 25 & Bucharest & 5 & 25 \\
\hline Turkey & Adana & 5 & 25 & Adana & 5 & 25 & Adana & 5 & 25 \\
\hline Australia & Sydney & 5 & 25 & Sydney & 5 & 25 & Sydney & 5 & 25 \\
\hline Germany & Mannheim & 5 & 25 & Mannheim & 5 & 25 & Mannheim & 5 & 25 \\
\hline \multicolumn{2}{|c|}{ Total } & 25 & 125 & Total & 25 & 125 & Total & 25 & 125 \\
\hline
\end{tabular}

Note: $\mathrm{n}^{\mathrm{g}}$ : Number of sample groups; $\mathrm{n}^{\mathrm{p}}$ : Number of group participants

Table 2: Data of the participants.

\begin{tabular}{|c|c|c|c|c|c|c|c|}
\hline \multicolumn{2}{|c|}{ Variables } & \multirow{2}{*}{$\begin{array}{c}\mathbf{n} \\
183\end{array}$} & \multirow{2}{*}{$\begin{array}{c}\text { \% } \\
48,8 \\
\end{array}$} & \multicolumn{2}{|c|}{ Variables } & \multirow{2}{*}{$\begin{array}{c}\mathbf{n} \\
32\end{array}$} & \multirow{2}{*}{$\begin{array}{c}\% \\
8,53 \\
\end{array}$} \\
\hline Condor & Male & & & \multirow{4}{*}{ Term of Office } & Less than 1 year & & \\
\hline Genuer & Female & 192 & 51,2 & & 1-5 years & 45 & 12,00 \\
\hline \multirow{4}{*}{ Age } & $21-26$ & 77 & 20,53 & & $6-10$ years & 63 & 16,8 \\
\hline & $27-32$ & 63 & 16,8 & & 11 years and over & 235 & 62,67 \\
\hline & $33-38$ & 121 & 32,27 & \multirow{2}{*}{ Marital Status } & Single & 103 & 27,47 \\
\hline & 39 and over & 114 & 30,4 & & Married & 272 & 72,53 \\
\hline \multirow{2}{*}{ Education Level } & Bachelor's Degree & 302 & 80,53 & & & & \\
\hline & Master's Degree & 73 & 19,47 & & & & \\
\hline \multicolumn{2}{|c|}{ Total } & 375 & 100 & & & 375 & 100 \\
\hline
\end{tabular}

\section{Analysis Method}

The phenomenological method, one of the qualitative research methods, was adopted in the study [15]. The data obtained through the interview were coded, classified, and categorized. Initially, the aim and scope of the research and the research question were determined: Can human psychology and behaviors be imitated in the organizational context? What are the imitation behaviors of the organization? Then, interview questions were determined based on the data obtained from the literature review. Interview questions were applied to 20 people in the context of semantic problems for reliability and presented to an expert committee of 7 people. After the necessary revisions were made, the interview questions were applied to the participants. The data obtained after the questions were applied to the participants were recorded and coded [16]. Associations and categories between experiences and phenomena were revealed [17]. The data obtained with semi-structured 
interview questions were subjected to relational analysis [18]. In this process, conceptualization, classification, and component analysis were applied [16-18]. The resulting concepts, categories, and titles were evaluated in the context of consistency [16-18]. Obtained findings were reported. In order to eliminate the bias of the researcher in the research findings, the findings were presented to a 7-person academic expert committee. The first reports of the researcher (R1) and expert committee (EC1) were compared. The second reports on the findings of the interviews conducted in the second year were compared with the R2 and EC2 (Figure 1).

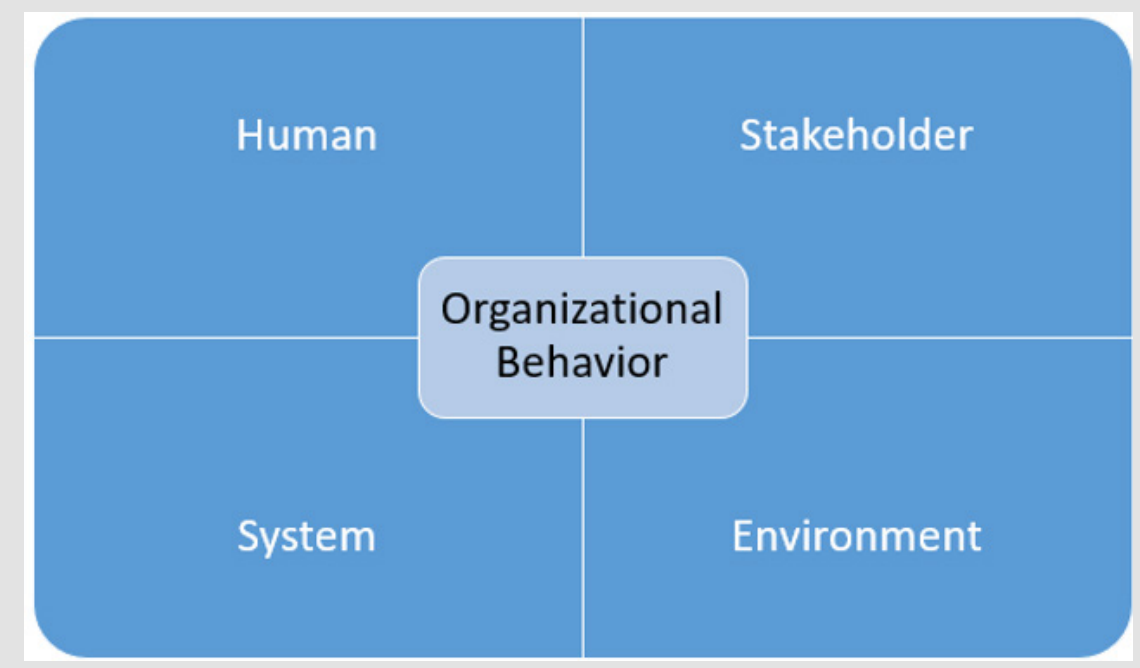

Figure 1: Organizational imitation.

\section{Results}

In the research, interviews were conducted for two main topics: organizational behavior imitation ability, organizational psychology imitation ability. Findings for both main issues were reported.

\section{Organizational Behavior Imitation Ability}

Organizational behavior is the whole of actions that emerge after interaction and communication with the external and internal environment. Research findings showed that organizations

Table 3: Defensive imitation ability in organizational behavior. imitate the behavior of humans, stakeholders, systems, and the environment.

Defense: Participants stated that defense is a behavior that is imitated via humans in organizations. Defense is a necessary behavior for organizations to maintain their sustainability, competitiveness, and enter new markets. This behavior is similar to the reactive actions of people against danger and threats. The similarities of the defensive behaviors in the human and organizational behaviors stated by the participants are shown in Table 3.

\begin{tabular}{|c|c|c|}
\hline Human Defensive Behavior & Organizational Defensive Behavior & Category \\
\hline Physical protection behavior & $\begin{array}{c}\text { Defensive behavior related to the protection of } \\
\text { the legal, organizational structure }\end{array}$ & Defense for existence \\
\hline Protection against attacks by opponents & Protection against attacks by competitors & Sustainability/adaptation defense \\
\hline Measures being taken against natural disasters & $\begin{array}{c}\text { Measures taken against environmental threats } \\
\text { and risks }\end{array}$ & Resource dependency defense \\
\hline Career planning and economic moves & Maintaining resources and saving measures & Organizational psychology defense \\
\hline Family, culture, social defense & $\begin{array}{c}\text { Organizational culture, climate, stakeholder, } \\
\text { customer defense }\end{array}$ \\
\hline
\end{tabular}

Strategic Attack: Strategy is important for the achievement of the long-term goals of the people and the organization. The results of the research showed that strategy was important for organizations to gain sustainable competitive advantage, and for the realization of multi-faceted goals such as performance, productivity, profitability, and innovation. Participants reported that organizations imitated human's offensive behavior. Research findings showed that organizations developed attack strategies against rival attacks. The strategic attack is developed by the organization if the emerging rival attacks are not eliminated in any other way. The strategic attack includes cyber-attack to obtain confidential information of competitors, prices, and wages to be offered in tenders, obtaining information about the employee and organizational culture, and learning the organizational structure. Participants explained that strategic attacks could be a result of rival attacks. 
Passive Action: Passive action is the acceptance of existing events without reacting or taking active action except for defense and attack. The results of the research indicated that such actions were carried out in order not to damage the relations with competitors, stakeholders, and customers. Participants stated that passive action is necessary in cases where resource dependence, lack of infrastructure, high competitiveness, and relationships with suppliers were sensitive. Participants stated that people take such actions when their interests require it and that leaders and managers reflect these behaviors to the organization in their decisions about the organization.

Organizational Psychology Imitation Ability: Organizational psychology is an emerging discipline that is effective in the development of psychological factors such as organizational employee behaviors, organizational management style, leadership characteristics, occupational health and safety, ergonomics, commitment, and tendencies. Organizational psychology deals with the effects of individual and group behaviors on the organization and its environment. Psychological factors affect many factors such as performance, commitment, profitability, productivity, sustainability, vision, customer satisfaction, consumer preferences, promotion, and quality management in the organization. Organizational psychology provides the development of skills, harmony, career development, and self-realization in the employeeorganization relationship. The research findings demonstrated that the result-based behaviors revealed by human psychology are imitated by the organization. The participants stated that the use of vehicles or driving cars by humans was similar to the management of the organization, and some tactics related to vehicle use or car drive were used in the management of the organization (Table 4).

Table 4: Imitation ability in organizational psychology.

\begin{tabular}{|c|c|c|}
\hline Human Psychology & Organizational Psychology & Descriptions \\
\hline $\begin{array}{l}\text { Traffic psychology (psycho technical } \\
\text { ability) }\end{array}$ & Ability to manage the organization & $\begin{array}{l}\text { The management of the organization in accordance with } \\
\text { the mission and vision. }\end{array}$ \\
\hline Health and clinical psychology & $\begin{array}{l}\text { Developing a psychological strategy to prevent } \\
\text { the organization from getting rigor mortis }\end{array}$ & $\begin{array}{l}\text { Developing the behavioral, psychological, and emotional } \\
\text { aspects of employee performance in the organization. }\end{array}$ \\
\hline Training psychology & Training of employees and stakeholders & $\begin{array}{l}\text { Developing, improving, and sustaining relationships and } \\
\text { interactions with employees, groups, teams, departments, } \\
\text { stakeholders, and customers. }\end{array}$ \\
\hline Forensic psychology & $\begin{array}{c}\text { Elimination/limitation of illegal behavior of } \\
\text { organizations }\end{array}$ & $\begin{array}{l}\text { Avoiding unfair competition, cybercrime, information } \\
\text { theft, unfair management, bid-rigging, fraud. }\end{array}$ \\
\hline Counseling psychology & Employees, stakeholders, customers & $\begin{array}{l}\text { Developing positive organizational psychology. } \\
\text { Occupational, workplace, job, workplace, and employee } \\
\text { harmony, focusing on solving problems related to work- } \\
\text { family balance, developing a strategy. }\end{array}$ \\
\hline
\end{tabular}

According to the other finding of the research on the ability to imitate in organizational psychology, health and clinical psychological behaviors are imitated in order for the organization to exist in systems (economic, legal, sector, etc.). The participants stated that the rehabilitation and treatment processes required to eliminate the psychological factors that cause people's bad habits also occurred in organizations. The participants reported that the emotional, behavioral, and psychological support necessary for the protection of the in-organizational psychological health of the employees was provided by the organizations. In addition, the results of the research revealed that remedial behaviors in this direction would positively affect the organizational climate and provide important outputs in performance, organizational commitment, and productivity. Training is a necessary factor that enables the improvement of the adaptation and commitment of the employees to the job, workplace, and organization through coaching and mentoring. Psychology development behaviors in this direction ensure harmony in the employee-organization-environment triangle. Thus, customer satisfaction, employee loyalty, and the sustainability of the organization can gain positive momentum.
The results of the research revealed that behavioral tendencies of training psychology were imitated in the organization. The criminal tendencies of humans may also cause a tendency to commit crimes in the management of the organization. In other words, it is possible for the managers or employees of the organization to use the organization as a mediator in the context of committing a crime.

Illegal behaviors within the organization and rewarding these behaviors may cause the organization to imitate the crime. The findings showed that managers have a tendency to commit crimes and employees have flexible thinking about committing crimes. On the other hand, the findings revealed that human behaviors of organizations to avoid behaviors aimed at eliminating these tendencies were imitated in the organization. Participants reported that positive psychology was imitated in the organization. It was stated by the participants that positive well-being, commitment, meaningfulness, positive emotion, achievement, and compassion improved the sense of organizational justice and revealed the elements of psychological capital. Motivation, personal and professional development, and employee-oriented positive 
approach help the development of organizational culture by improving the organizational climate. The positive psychology behaviors of human beings are imitated by the organization and strategic steps are taken to develop institutionalism and organizational culture.

\section{Discussion}

Organizational behavior and psychology are under the influence of human psychology [19-21]. This effect causes organizations to be shaped under the reflections of human behavior [22-23]. Researches have examined organizational psychology in the context of the social network, learning, strategies, and practices [24-30]. There is no study in the literature on the imitation of human behavior and psychology by the organization. This study is the first study in this direction. The findings of the study showed that behavioral elements of human psychology were imitated by the organization. In behavior and psychology, imitation behaviors are performed for the sustainability of the organization, economic freedom, access to resources, and existing in the system. According to research findings, organizations imitate systems, stakeholders, environment, human behavior, and human psychology. The ability to imitate organizational behavior is realized through the defense, strategic attack, and passive action. Managers and leaders have a high impact on imitating these behaviors. For this reason, a control mechanism/system should be established to reflect the behavior of the leader or manager to the organization in controlling the imitation-based behaviors of the organization.

The self-control that will be created in the behavior imitation of the organization will prevent strategic deviations. It is especially important to limit and control aggressive/attack/offensive behaviors. Counterattack may not cause ethical consequences in order to eliminate attacks from competitors. The factors that cause this situation should be determined strategically.Organizational psychology management is important in the efficient management of human resources. The findings of the research show that human psychology is imitated by the organization. Human psychology reflects its effects on administrative/management, health, training, forensic and positive psychology to the organization. This reflection provides the development of imitation ability in the organization. Negative outcomes that may arise in the imitation-based behavior of organizational psychology should be determined managerially and necessary precautions should be taken. Necessary measures should be taken in human resources management so that negative outcomes that may arise from the psychology of the employees do not cause imitation of the organization.

On the other hand, excess in positive psychology can create a blind spot about reality. For this reason, a balanced strategy should be developed in the management of imitation-based behaviors in organizational psychology. Research revealed the development of imitation ability in organizational behavior and psychology. Although this result reveals an important topic in organizationemployee-stakeholder-customer relations and interactions, repeating the study in samples with different cultural characteristics will contribute to the literature. It is recommended that future studies develop a scale for imitation behaviors of organizations. In addition, it is important and necessary to conduct more studies examining the relationship between organizational psychology and human psychology. Although the study was carried out by adopting the qualitative research method, it includes limitations such as the generalizability of the results and cultural differences. In addition, not all of the coding stages were included in the study. Due to the details of the qualitative findings, making the readers move away from the importance of the findings of the result causes the study to deviate from the purpose. However, the fact that not all of the coding stages were included in the study is an important limitation.

\section{Conclusion}

Research results revealed that human behavior and psychology are imitated by organizations. According to the coding results, three types of imitation behaviors were identified in the context of organizational behavior: defense, strategic attack, passive action behaviors. Defensive imitation ability in organizational behavior consisted of defense for existence, competition defense, sustainability/adaptation defense, resource dependency defense, organizational psychology defense. It was determined that the imitation ability of organizational psychology consisted of traffic (psycho technical ability), health and clinical, training, forensic, and counseling psychology categories.

\section{References}

1. Barrett L, Dunbar R, Lycett J (2002) Human evolutionary psychology. Princeton University Press, pp. 448.

2. Dean LG, Kendal RL, Schapiro SJ, Thierry B, Laland KN (2012) Identification of the social and cognitive processes underlying human cumulative culture. Science 335(6072): 1114-1118.

3. Ballerini C, Aldinucci A, Luccarini I, Galante A, Manuelli C, et al. (2013) Antagonism of histamine H4 receptors exacerbates clinical and pathological signs of experimental autoimmune encephalomyelitis. British journal of pharmacology 170(1): 67-77.

4. Brehmer B (1992) Dynamic decision making: Human control of complex systems. Acta psychologica 81(3): 211-241.

5. Andry P, Gaussier P, Nadel J, Hirsbrunner B (2004) Learning invariant sensorimotor behaviors: A developmental approach to imitation mechanisms. Adaptive behavior 12(2): 117-140.

6. Campbell ME, Cunnington R (2017) More than an imitation game: Top-down modulation of the human mirror system. Neuroscience \& Biobehavioral Reviews 75: 195-202.

7. Meltzoff AN, Decety J (2003) What imitation tells us about social cognition: a rapprochement between developmental psychology and cognitive neuroscience. Philosophical Transactions of the Royal Society of London. Series B: Biological Sciences 358(1431): 491-500.

8. Rizzolatti G, Craighero L (2004) The mirror-neuron system. Annu Rev Neurosci 27: 169-192. 
9. Özsungur F (2020) The Effects of the Menstruation Period on the Perception of Aging via Imitation of Menopause. International Journal of Eurasia Social Sciences 11(40): 458-492.

10. Özsungur F (2020) Theoretical Foundations of Latent Aging and Imitation of Aging. Archives in Neurology \& Neuroscience 7(2): 1-5.

11. Özsungur F (2020) The Psychological Effects of Systemic Lupus Erythematosus: The Imitator of Aging LymphoSign Journal 7(1): 37-45.

12. Özsungur F (2019) A Research on Relationship Between Latent Aging and Chronic Lymphocytic Thyroiditis. Biomedical Journal of Scientific \& Technical Research (BJSTR) 23(5): 17761-17763.

13. Rizzolatti G (2005) The mirror neuron system and its function in humans. Anatomy and embryology 210(5-6): 419-421.

14. Buccino G, Binkofski F, Riggio L (2004) The mirror neuron system and action recognition. Brain and language 89(2): 370-376.

15. Giorgi A (1975) An application of phenomenological method in psychology. Duquesne studies in phenomenological psychology 2: 82103.

16. Willig C (2007) Reflections on the use of a phenomenological method. Qualitative research in psychology 4(3): 209-225.

17. Morrow R, Rodriguez A, King N (2015) Colaizzi's descriptive phenomenological method. The psychologist 28(8): 643-644.

18. Giorgi A (2006) Difficulties encountered in the application of the phenomenological method in the social sciences. Análise psicológica 24(3): 353-361.

19. Leavitt HJ, Bass BM (1964) Organizational psychology. Annual review of psychology 15(1): 371-398.

20. Miner JB (1992) Industrial-organizational psychology. In: Miner JB (Edt.)., McGraw-Hill Book Company, USA.

\section{ISSN: 2574-1241}

DOI: 10.26717/BJSTR.2021.36.005925

Fahri Özsungur. Biomed J Sci \& Tech Res

(C) (P) This work is licensed under Creative Commons Attribution 4.0 License

Submission Link: https://biomedres.us/submit-manuscript.php
21. Borman WC, Ilgen DR, Klimoski RJ (2003) Handbook of psychology: Industrial and organizational psychology (12 $2^{\text {th }}$ Edn.).,. In: Borman WC, Ilgen DR, Klimoski RJ (Eds.)., John Wiley \& Sons Inc, USA.

22. Nahavandi A, Denhardt RB, Denhardt JV, Aristigueta MP (2013) Organizational behavior ( $1^{\text {st }}$ Edn.)... In: Nahavandi A, Denhardt RB, Denhardt JV, Aristigueta MP (Eds.)., Sage Publications, USA.

23. Robbins SP, Judge TA (2013) Organizational behavior. In: Robbins SP, Judge TA (Eds.)., (Vol 4). New Jersey: Pearson Education.

24. Bond MH, Smith PB (1996) Cross-cultural social and organizational psychology. Annual review of psychology 47(1): 205-235.

25. Jex SM, Britt TW (2014) Organizational psychology: A scientistpractitioner approach. In: Jex SM, Britt TW (Eds.)., John Wiley \& Sons, USA.

26. Aamodt MG (2015) Industrial/organizational psychology: An applied approach ( $6^{\text {th }}$ Edn.).,. In: Aamodt MG (Edt.)., Cengage Learning, USA.

27. Van Dick R(2001)Identificationin organizational contexts: Linking theory and research from social and organizational psychology. International Journal of Management Reviews 3(4): 265-283.

28. Triandis HC, Dunnette MD, Hough LM (1994) Handbook of industrial and organizational psychology. In: Triandis HC, Dunnette MD, Hough LM (Eds.)., Consulting Psychologists Press, USA.

29. Kanfer R (1990) Motivation theory and industrial and organizational psychology. Handbook of industrial and organizational psychology 1(2): 75-130.

30. Lefkowitz J (2017) Ethics and values in industrial-organizational psychology. In: Lefkowitz J (Edt.)., Taylor \& Francis, USA, pp. 618.

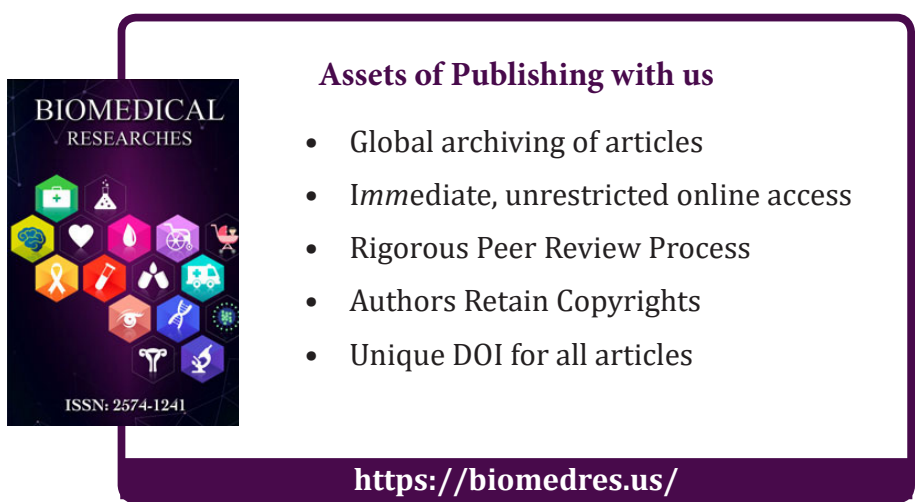

